\title{
ПОСТПОГРЕБАЛЬНЫЕ ОБРЯДЫ САРМАТСКОГО НАСЕЛЕНИЯ ЗАПАДНОГО КАЗАХСТАНА (на примере могильника Кайынбулак II)
}

\section{(C) 2020 г. Арман Ауганович Бисембаев ${ }^{1}$, Алексей Иванович Хаванский ${ }^{1}$}

\begin{abstract}
${ }^{1}$ кандидат исторических наук, старший научный сотрудник, филиал Института apхеологии им. А. Х. Маргулана, г. Нур-Султан, Казахстан. E-mail: abissembaev@mail.ru

${ }^{1}$ кандидат исторических наук, старший научный сотрудник, филиал Института археологии им. А. Х. Маргулана, г. Нур-Султан, Казахстан. E-mail: Arkaim01@yandex.ru
\end{abstract}

Аннотация. Целью статьи является публикация и анализ археологических материалов сарматского могильника Кайынбулак II со следами постпогребальных ритуалов. В погребении 3 были произведены манипуляции с останками погребенного. Это не было ограбление (наконечники стрел, акинак и сосуды находились in situ). Отмечается избирательность и аккуратность в нарушении скелета. Нарушена только левая часть грудной клетки (место расположения сердца), отчленен и отложен в сторону череп. Плечевая кость была вынута, однако потом положена обратно, правда с разворотом на $180^{\circ}$. В погребении 4 деревянное перекрытие над погребением было частично снято, а потом положено обратно. Под ним находились кости животных в виде типичных «кухонных остатков» (разрозненные и раздробленные). Находились они в слое серой супеси, которая покрывала погребенного. Это говорит о том, что кости животных были помещены в погребение уже после того, как оно было заполнено грунтом. Таким образом, вероятным выглядит предположение, что кости являются результатом поминальных ритуалов. После проведения поминальной трапезы часть перекрытия над погребением 4 была разобрана, а кости сброшены в погребение. Возможно, таким образом погребенный становился символическим участником поминальной трапезы. В обоих случаях ритуалы проводились через значительный промежуток времени (останки прошли стадию скелетирования, а погребения частично заполнились грунтом). Вероятно, общей курганной насыпи в то время еще не существовало, и участники ритуала точно определяли место погребения. При этом они знали расположение погребенных, то есть были и участниками захоронения.

Ключевые слова: археология, Западный Казахстан, сарматы, погребальный обряд, постпогребальные ритуалы

\section{БАТЫС ҚАЗАҚСТАННЫН САРМАТ ТҰРҒЫНДАРЫНЫН КАБІРДЕН КЕЙІНГІ РӘСІМДЕРІ (Қайыңбұлақ II бейітінің мысалында)}

\section{Арман Ауганұлы Бисембаев ${ }^{1}$, Алексей Иванович Хаванский ${ }^{1}$}

\footnotetext{
${ }^{1}$ т.ғ.қ., АҒҚ, А. Х. Марғұлан атындағы Археология институтының филиалы Нұр-Сұлтан қ., Қазақстан. E-mail: abissembaev@mail.ru

${ }^{1}$ т.ғ.қ., АҒҚ, А. Х. Марғұлан атындағы Археология институтының филиалы Нұр-Сұлтан қ., Қазақстан. E-mail: Arkaim01@yandex.ru
}

Аннотация. Мақаланың мақсаты - сарматтық Қайыңбұлақ II қорымының археологиялық материалдарын жерлеуден кейінгі рәсімдердің іздерімен жариялау 
Бисембаев А.А., Хаванский А.И. Постпогребальные обряды сарматского населения ...

және талдау. 3 жерлеуде жерленгендердің қалдықтарымен манипуляциялар жасалды. Бұл тонау емес еді (жебе ұштары, акакалар мен ыдыстар жағдайында болған). Қаңқа бұзылған кезде селективтілік пен дәлдік байқалады. Кеуде куысының сол жақ бөлігі ғана (жүректің орналасқан жері) сынған, бас сүйегі сынған және бөлек қойылған. Гумер алынып тасталды, бірақ 1800-ге бұрылған болса да, қайтадан қалпына келтірілді. 4 жерлеуде жерлеу үстіндегі ағаш төбесіжартылай алынып, содан кейін қайтадан қойылды. Оның астында жануарлардың сүйектері әдеттегі «ас қалдықтары» (шашыраңқы және бөлінген) түрінде болды. Олар көмілген жерді жауып тұрған сұр құмды саздақ қабатында болды. Бұл жануарлардың сүйектері топырақпен толтырылғаннан кейін жерленген жерге қойылғандығын білдіреді. Осылайша, сүйектер жерлеу рәсімдерінің нәтижесі болғанға ұқсайды. Жерлеу тойынан кейін 4 жерлеу төбесіндегі төбенің бөлігі бөлшектеліп, сүйектер жерленген жерге құлады. Мүмкін, осылайша марқұм еске алу дастарханында символдық қатысушы болған шығар. Екі жағдайда да салт-жоралар біршама уақыт аралығында орындалды (қалдықтар қаңқа сатысынан өтті, жерлеулер ішінара топыраққа толды). Мүмкін, ол кезде жалпы жерлеу қорғаны әлі болған жоқ, ал рәсімге қатысушылар жерлеу орнын дәл анықтаған. Оның үстіне, олар жерленген жерді білді, яғни олар жерлеудің қатысушылары болды.

Түйін сөздер: археология, сарматтар, Батыс Қазақстан, жерлеу рәсімі, жерлеуден кейінгі рәсімдер

\section{POST-GRAVE RITES OF THE SARMATIAN POPULATION OF WESTERN KAZAKHSTAN (on the example of the grave Kayynbulak II)}

\section{Arman A. Bisembayev ${ }^{1}$, Alexey I. Khavansky ${ }^{1}$}

${ }^{1}$ Candidate of Historical Sciences, Senior Researcher, Branch of the A. Kh. Margulan Archeology Institute, Nur-Sultan, Kazakhstan. E-mail: abissembaev@mail.ru ${ }^{1}$ Candidate of Historical Sciences, Senior Researcher, Branch of the A. Kh. Margulan Archeology Institute, Nur-Sultan, Kazakhstan. E-mail: Arkaim01@yandex.ru

Abstract. The purpose of the article is the publication and analysis of archaeological materials of the Sarmatian burial ground Kayynbulak II with traces of post-funeral rituals. In burial 3, manipulations were made with the remains of the buried. This was not a robbery (arrowheads, akinak and vessels were in situ). Selectivity and accuracy in violation of the skeleton are noted. Only the left part of the chest (the location of the heart) is broken, the skull is severed and set aside. The humerus was removed, but then laid back, though with a turn of $180^{\circ}$. In burial 4 , the wooden ceiling above the burial was partially removed, and then laid back. Under it were the bones of animals in the form of typical "kitchen residues" (scattered and fragmented). They were in a layer of gray sandy loam, which covered the buried. This suggests that the bones of animals were placed in the burial after it was filled with soil. Thus, it seems likely that the bones are the result of funeral rituals. After the funeral feast, part of the ceiling over burial 4 was disassembled, and the bones dropped into the burial. Perhaps in this way the deceased became a symbolic participant in the memorial meal. In both cases, the rituals were performed over a considerable period (the remains passed the skeleton stage, and the burials were partially filled with soil). Probably, a common burial mound at that time did not yet exist, and the participants in the ritual accurately determined the place of burial. Moreover, they knew the location of the buried, that is, they were also participants in the burial.

Keywords: archaeology, Sarmatians, Western Kazakhstan, funeral rite, post-funeral rituals 


\section{Введение}

Постпогребальные

обряды (нарушение погребения, следы поминальных ритуалов и т.д.) все чаще привлекают к себе внимание исследователей [Очир-Горяева, 2016; Семёнов, Килуновская, 2016; Яценко, Килуновская, 2016; Джумабекова, Базарбаева, 2019]. Совершенствование методики полевых исследований и анализа материала позволяют более полно узнать религиозные взгляды древнего населения Казахстана, которые были «зашифрованы» в погребальном обряде.

Целью данной статьи является публикация и анализ археологических материалов сарматского могильника Кайынбулак II со следами постпогребальных обрядов.

Описание материала

Могильник Кайынбулак II расположен в Актюбинской области, в 25 км к северу от г. Актюбинска (рис. 1). Курган 4 располагался на небольшой возвышенности в междуречье рек Жаксы-Каргалы и Бутак. Курган был распахан и в рельефе практически не читался.

Планиграфия кургана 4 (рис. 2). На подкурганной площадке было выявлено пять погребений: три из них (№ $1,3,4)$ были выстроены в цепочку, ориентированную по линии С3-ЮВ. Погребение 2 было совершено в насыпи у западного края п. 3. Погребение 5, вероятнее всего, было совершено в насыпи и разрушено распашкой. Постпогребальные обряды были зафиксированы в погребениях № 3 и 4. Остановимся на них подробно.

Погребение № 3 (рис. 3-4) расположено в 2 м к западу от «0». На глубине 0,3 м от края могильной ямы выявлены разрозненные фрагменты дерева (вероятно, остатки пере-

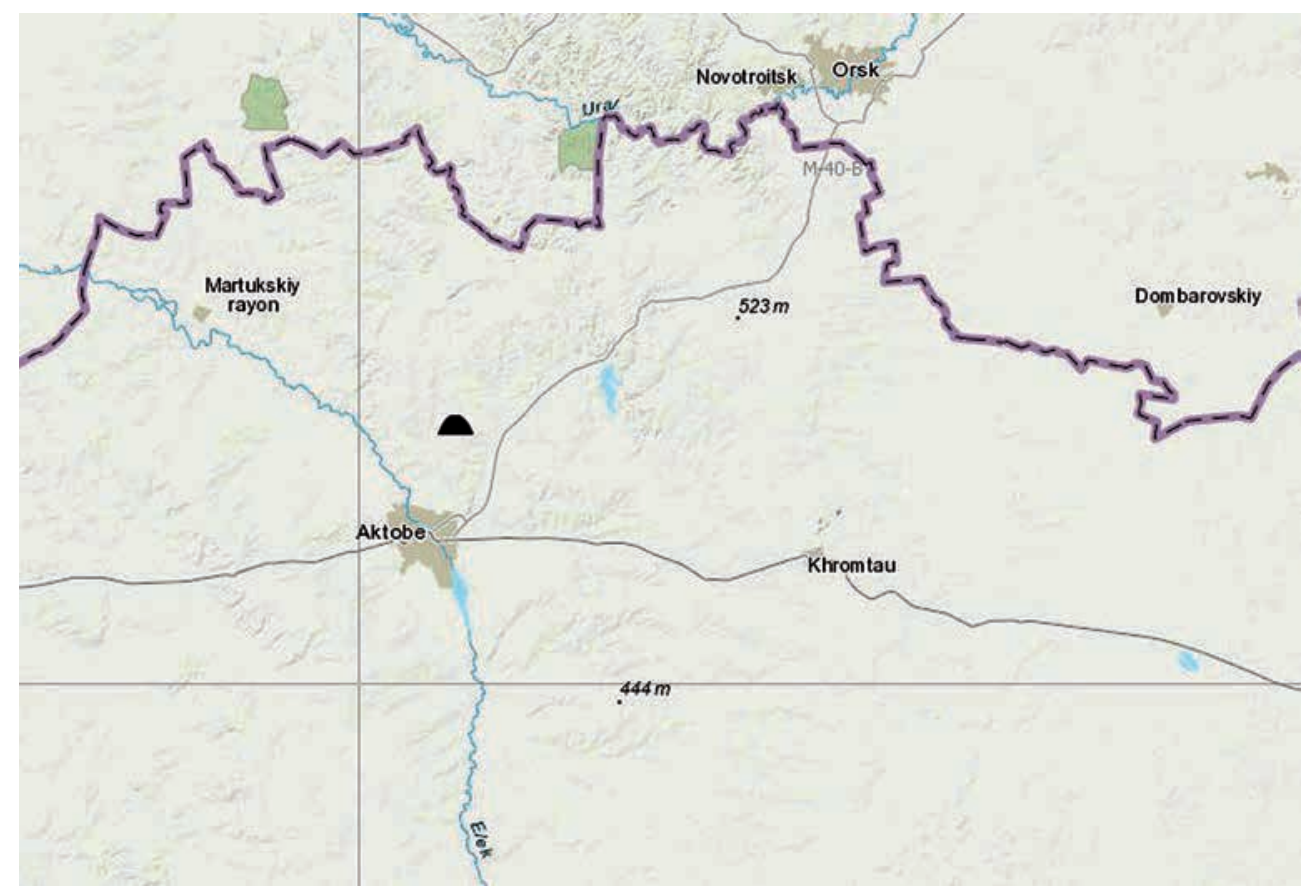

Рис. 1. Место расположения кургана 4 могильника Кайынбулак II

Fig. 1. The location mound 4 of the burial ground Kayynbulak II 
Бисембаев А.А., Хаванский А.И. Постпогребальные обряды сарматского населения ...

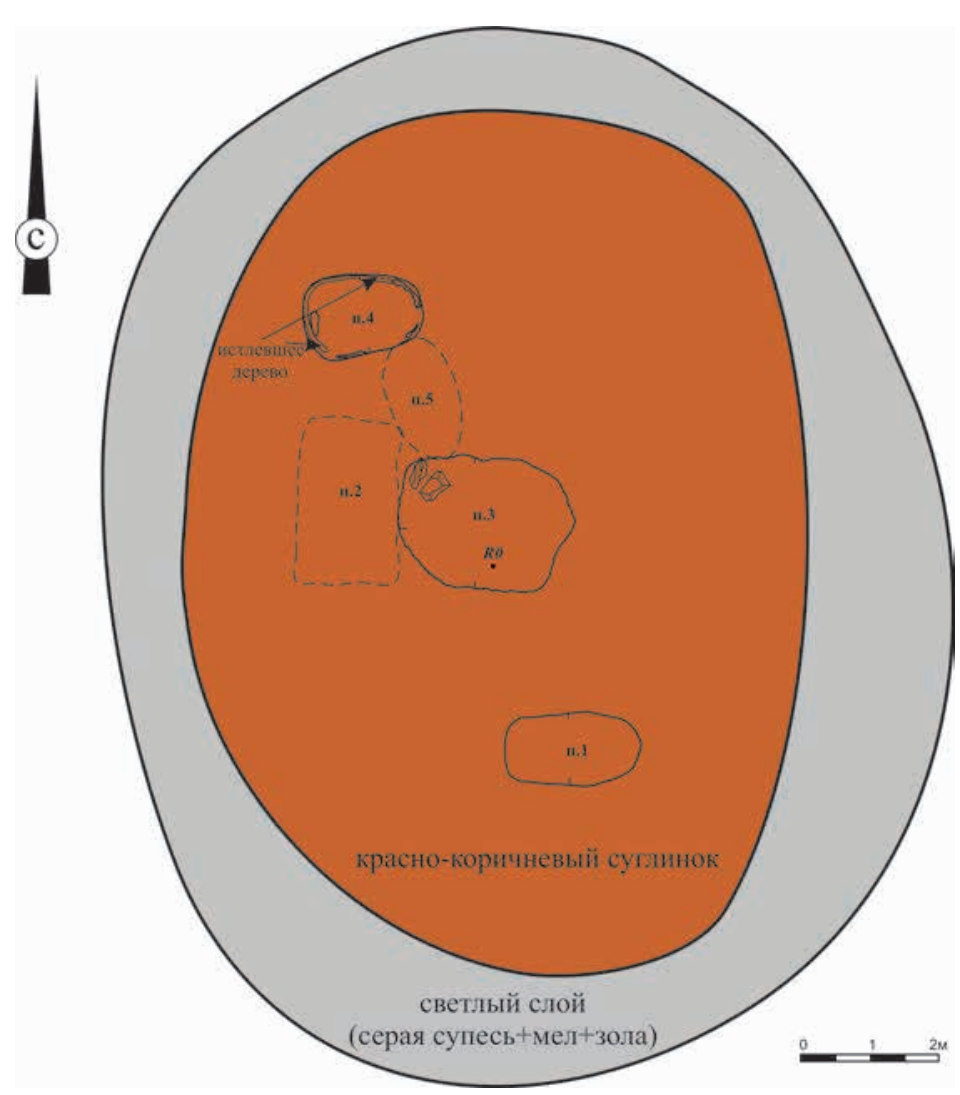

Рис. 2. План кургана 4 могильника Кайынбулак II

На уровне дна яма вновь расширяется за счет подбоев во всех четырех стенках, глубина подбоев достигает 0,5 м. Дно зафиксировано на уровне -165 см от «0». Размеры на уровне дна: длина $-2,35$ м, ширина 1,8 м. На дне были расчищены останки двух индивидов зрелого возраста.

Погребен ный № 1 находился в северной части ямы и покоился в положении вытянуто на спине, руки вдоль тела, головой на восток. Около костей предплечья наFig. 2. The plan of the mound 4 of the burial ground Kayynbulak II ходились лопатки мелкого рогатого скота. У северной

крытия). В восточной части погребения обнаружен камень размерами $20 \times 20 \times 17$ см. Засыпь могильной ямы - очень плотная гумусированная серая супесь. На уровне -140/-150 см от «0» в северной части ямы расчищены наконечники стрел. Наконечники не образуют какого-либо строго очерченного скопления и рассеяны практически по всей северной половине ямы. На уровне материка яма имела овальную форму и была ориентирована по линии 3-В. Длина - 2,55 м, ширина - 1,9 м. Стенки верхней части наклонные вовнутрь до $45^{\circ}$. К уровню -90 см от «0» размеры ямы сужались до 1,8 м в длину и 1,3 м в ширину. стенки в подбое - скопление костей № 1 (ребра/бок лошади или крупного рогатого скота), поверх - железный нож. Ниже - скопление костей № 2, оно включает в себя кости крупного и мелкого рогатого скота. К западу от этих скоплений находятся сосуды № 1 и 2.

Погребенный № 2 находился в южной части ямы. Положение аналогично погребенному 1. У погребенного № 2 отсутствуют череп, часть костей обеих рук и левая часть ребер грудной клетки.

В южном подбое, напротив погребенного № 2, находится череп, стоящий на основании, нижняя челюсть 


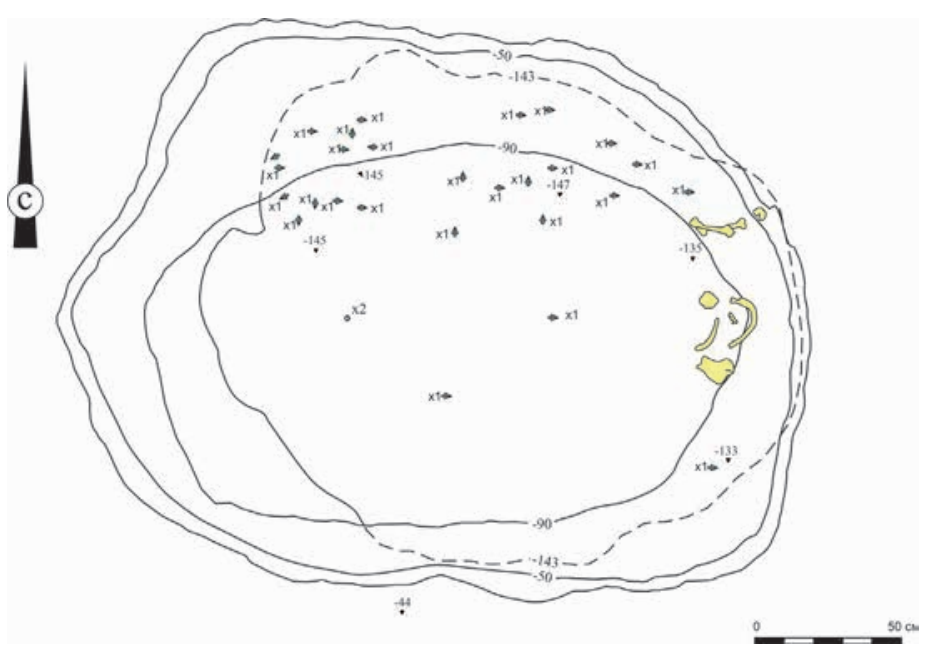

Рис. 3. Курган 4 могильника Кайынбулак II. Погребение № 3. Промежуточная зачистка могильной ямы на уровне -140 - 150 см: 1 - бронзовые наконечники стрел; 2 - бусина

Fig. 3. Barrow 4 of the Kayinbulak II burial ground. Burial № 3. Intermediate cleaning of the grave pit at the level of -140 - $150 \mathrm{~cm}: 1$-bronze arrowheads; 2 - bead

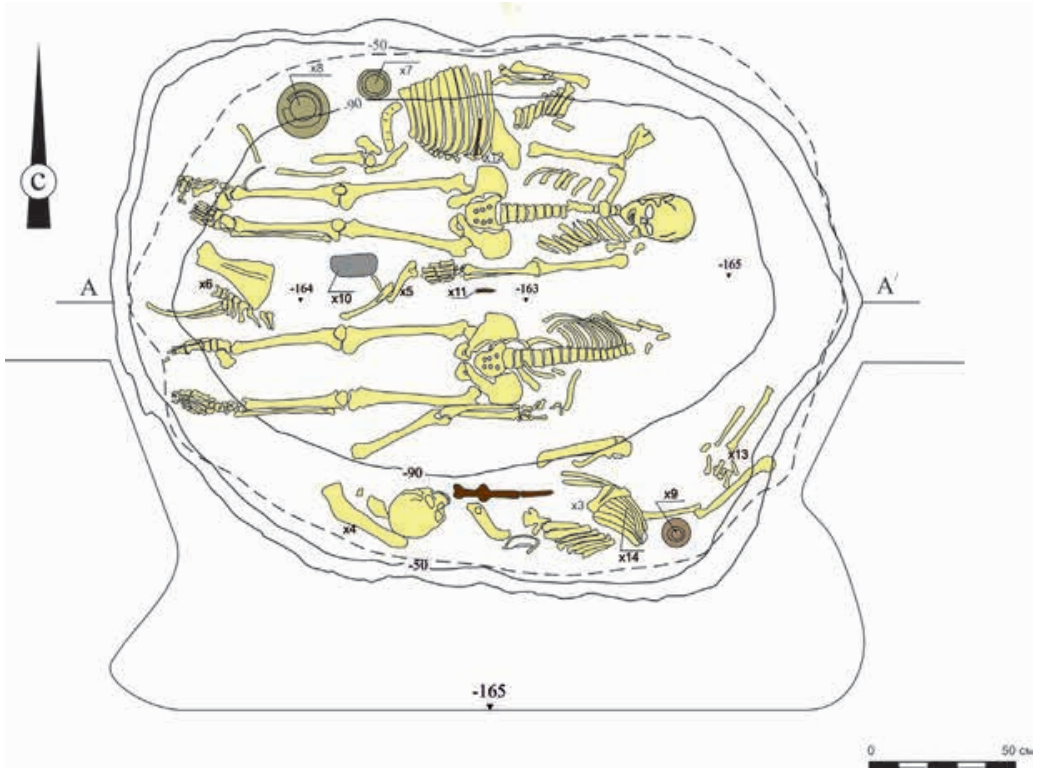

Рис. 4. Курган 4 могильника Кайьнбулак II. Погребение № 3. Дно могильной ямы: 1 - скопление костей № 1; 2 - скопление костей № 2; 3 - скопление костей № 3; 4 - скопление костей № 4; 5 - скопление костей № 5; 6-скопление костей № 6; 7 - сосуд № 1; 8 - сосуд № 2; 9 - сосуд № 3; 10 - каменное точило; 11 - железный нож; 12 - фрагмент железного ножа; 13 - фрагмент железного изделия; 14 - фрагмент железного ножа

Fig. 4. Barrow 4 of Kayinbulak II burial ground. Burial № 3. The bottom of the grave pit; 1-accumulation of bones No.; 2-accumulation of bones No. 2; 3-accumulation of bones No. 3; 4-accumulation of bones No. 4; 5-cluster of bones No. 5; 6-cluster of bones No. 6; 7-vessel No. 1; 8-vessel No. 2; 9-vessel No. 3; 10-stone sharpener; 11-iron knife; 12 fragment of an iron knife; 13-fragment of an iron product; 14-fragment of an iron knife 
Бисембаев А.А., Хаванский А.И. Постпогребальные обряды сарматского населения ...

лежит отдельно от черепа в 0,5 м к востоку от него. Около бедренной и тазовой костей находилась левая рука, суставы в сочленении, кости (в том числе мелкие кости кисти) - в анатомическом порядке. Однако рука была развернута на $180^{\circ}$ таким образом, что головка плечевой кости находится возле коленного сустава, а кисть - в районе таза. В юго-восточном углу зафиксированы кости правой руки без анатомического порядка, сваленные в кучу. Там же найдены обломки железного предмета.

В южном подбое к востоку от черепа зафиксирован железный акинак, лежащий рукоятью к черепу. Акинак имеет почковидное перекрестье и волютообразное навершие. В этом же подбое зафиксировано скопление костей № 3. В юго-западной части подбоя - скопление костей № 4.

Между погребенными на уровне тазовых костей обнаружен железный нож, на уровне коленных суставов скопление костей № 5 и каменное точило. Между костями стоп - скопление костей № 6.

Погребение 4 (рис. 5-7). Обнаружено в 5 м к северо-западу от центра кургана. На глубине 0,05 м от уровня материка выявлена бусина. В центральной части ямы на уровне 0,2 м от уровня материка - кость животного.

На уровне от -50 до -65 см от «0» выявлены остатки деревянного перекрытия. Ширина плах перекрытия до 20 см, толщина 5-7 см. Плахи уложены вдоль длинной оси ямы. Сохранились остатки коры светло-серого цвета (возможно, осина, т.к. кора тонкая). Целостность плах нарушена. Исходя из их расположения видно, что некоторые плахи были вынуты, а затем аккуратно положены обратно.

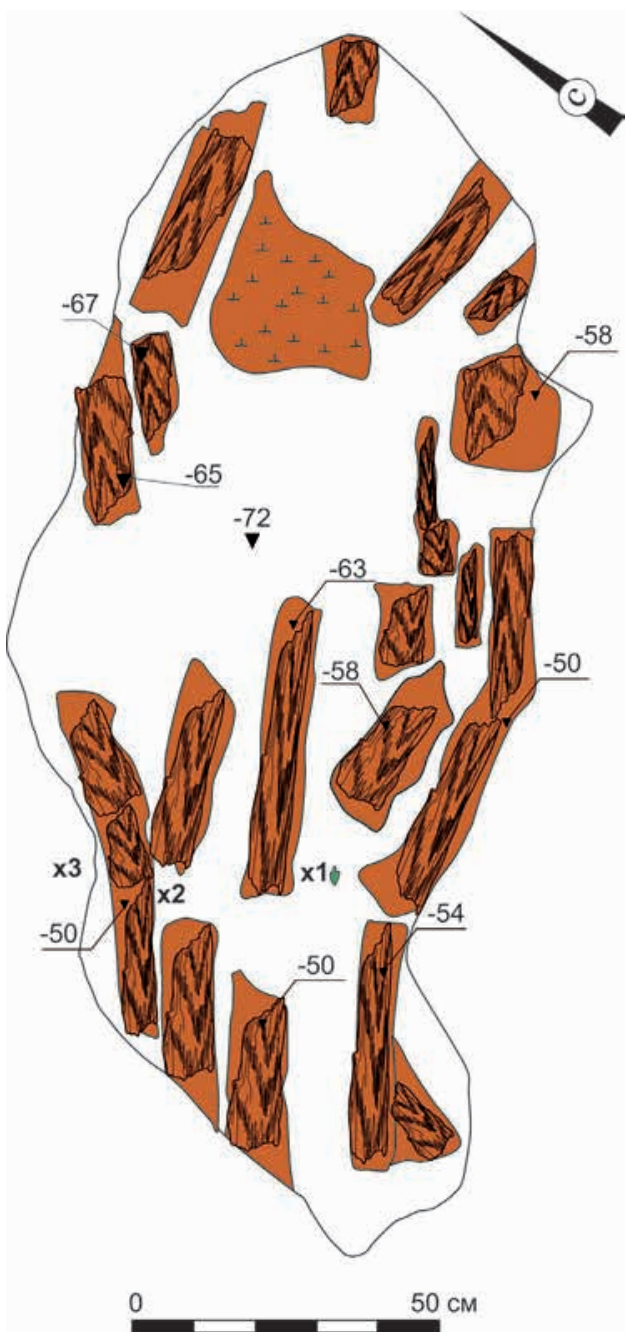

Рис. 5. Курган 4 могильника Кайынбулак II. Погребение № 4. Остатки деревянного перекрытия

Fig. 5. Mound 4 of the Kayinbulak II burial ground. Burial № 4. Remains of a wooden floor

Под перекрытием на уровне -90/-95 расчищены разрозненные кости животных. Кости лежат в слое серой супеси, которой и засыпано погребение. Ниже располагаются кости погребенного.

Погребение совершено в грунтовой яме. Западные углы ямы имеют подпрямоугольную форму, в восточной части яма имеет форму овала. 


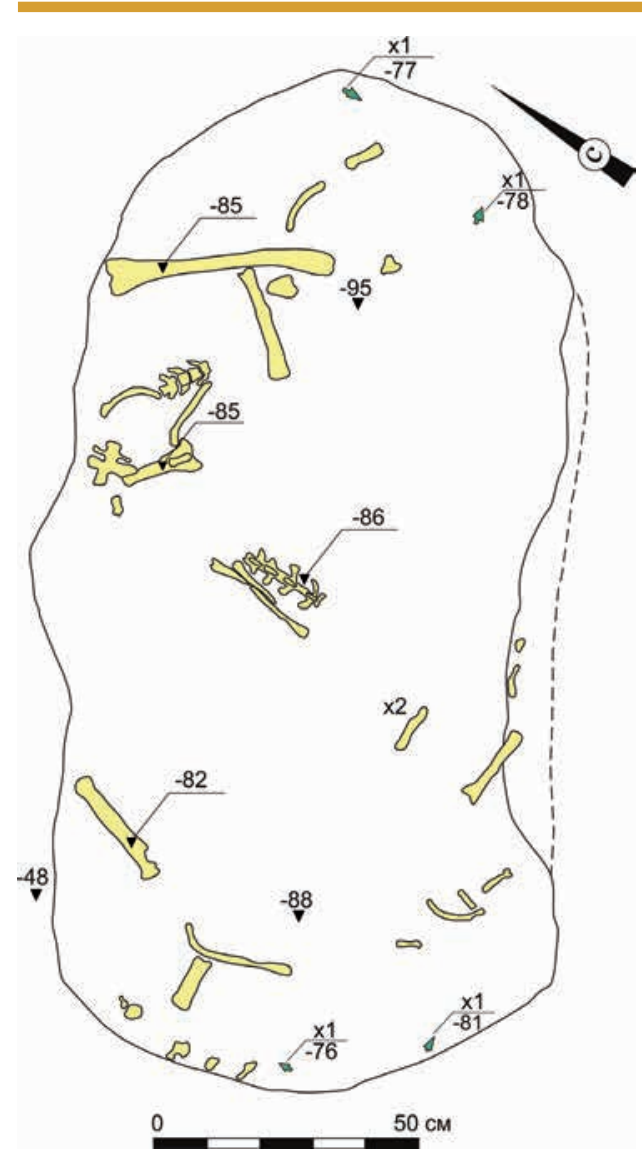

Рис. 6. Курган 4 могильника Кайынбулак II. Погребение № 4. Остатки под перекрытием: 1 - бронзовые наконечники стрел

Fig. 6. Barrow 4 of Kayinbulak II burial ground. Burial № 4. Remains under the ceiling: 1 - bronze arrowheads

Южная стенка ямы имеет небольшой подбой, глубиной 25-30 см. Дно находилось на уровне - 120 см. На дне ямы покоился индивид зрелого возраста. Погребенный находился в положении вытянуто на спине, руки вдоль тела, головой ориентирован на запад-югозапад. Череп имеет небольшой завал влево, к северу. Бедренная кость имеет следы зажившего перелома. В районе левого локтевого сустава находилась костяная лопаточка. В районе правого локтевого сустава - скопление бронзовых наконечников стрел. У южной стенки ямы находился глиняный сосуд, далее к востоку в подбое скопление костей лошади. Напротив правого коленного сустава у южной стенки крестец лошади. Поверх него - скопление гальки темно-серого цвета. У северной стенки ямы вдоль тазовой и бедренной костей находилось скопление костей мелкого рогатого скота (вероятно, полный скелет ягненка без головы).

Культурная атрибуция и датировка. Форма погребальных сооружений, положение погребенных головой к западу и востоку, акинак с почковидным перекрестьем и волютообразным навершием, тождественные формы сосудов из погребений № 1, 3 и 4 (плавнопрофилированные «бомбовидные» горшочки) говорит о том, что данный комплекс относится к одной группе населения савроматской культуры. Погребение 2, возможно, учитывая южную ориентировку, связано с формированием раннесарматской (прохоровской) культуры.

\section{Обсуждение результатов}

Таким образом, в погребениях № 3 и 4 были выявлены следы нарушения погребальной обрядности. В погребении 3 частично нарушены кости погребенного № 2. Отметим следующие детали. Во-первых, вряд ли имело место ограбление (по крайней мере, наконечники стрел, акинак и сосуды находились в целости). Вовторых, мы видим избирательность и аккуратность в нарушении скелета. Нарушена только левая часть грудной клетки (место расположения сердца) и отчленен череп. Плечевая кость была вынута, однако потом положена обратно, правда с разворотом на $180^{\circ}$.

Исходя из расположения останков погребенных, инвентаря и следов нарушения можно сделать вывод, что 
люди, нарушавшие его, знали расположение погребенных и целенаправленно искали останки погребенного № 2. Скорее всего, был прорыт ход, ведущий непосредственно к погребенному № 2. Это следует из того, что все остатки на дне могильной ямы находятся в целости. При том, что остатки погребенных и инвентарь очень плотно занимают дно погребения. Это даже создало определенные трудности при расчистке погребения. Тем более, если целью проникновения в погребение было только разрушение костей погребенного № 2, было бы невозможно оставить целыми остальные элементы погребения. Отметим также, что наконечники стрел располагались россыпью в 15 см выше дна могильной ямы в слое засыпи. Скорее всего, это является результатом действий нарушителей погребения. Вероятно, к моменту проникновения дно погребения было присыпано грунтом, нарушители наткнулись на колчан и выбросили стрелы в сторону, на грунт.

О том, что нарушение произошло через определенный промежуток времени говорит и то, что от скелета были свободно отсоединены кости рук, череп, челюсть. А это возможно только, если завершен процесс скелетирования.

Можно ли предположить цель проникновения в погребение № 3? Напрашивается вариант, что целью вторжения был широко известный ритуал «обезвреживания покойника». Он предполагает полное или частичное разрушение скелета погребенного, который при жизни доставлял неудобства соплеменникам. Действительно, в погребениях раннего железного века мы находим такие свидетельства, когда инвентарь остается в погребении,

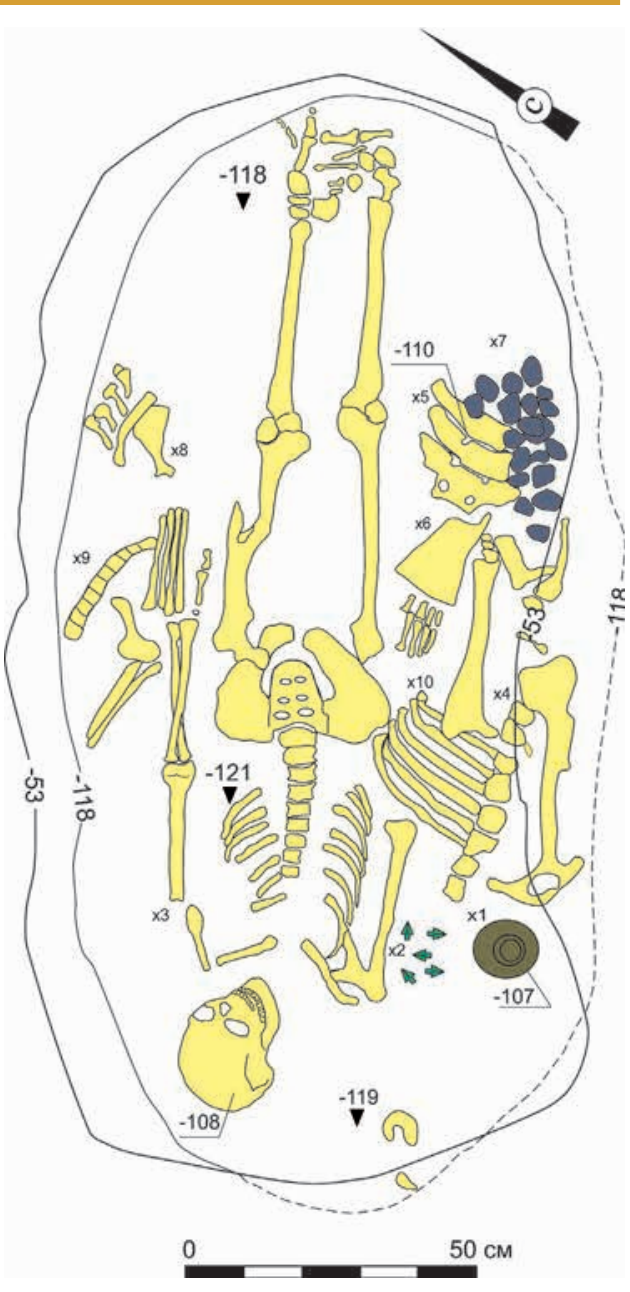

Рис. 7. Курган 4 могильника Кайынбулак II. Погребение № 4. Дно могильной ямы: 1 - глиняный сосуд; 2 - бронзовые наконечники стрел; 3 - костяная ложечка; 4 - скопление костей лошади; 5 - лопатка лошади; 6 - лопатка мелкого рогатого скота; 7 - скопление камней (галька); 8 - ребра мелкого рогатого скота; 9 - кости ягненка; 10 - фрагмент железного ножа

Fig. 7. Barrow 4 of the Kayinbulak II burial ground. Burial № 4. Bottom of the grave pit: 1 -jin vessel; 2 - bronze arrowheads; 3 - bone spoon; 4 -accumulation of horse bones; 5 - shoulder blade of a horse; 6 - scapula of small cattle;

7 - accumulation of stones (pebbles); 8 - ribs of small cattle; 9 - bones of a lamb; 10 - fragment of an iron knife 
а скелет полностью разрушен или от него остаются только отдельные кости.

В данном случае вряд ли мы можем с этим согласиться. Безусловно, определенное нарушение костей скелета имело место, но оно было произведено максимально аккуратно, можно даже сказать, уважительно.

Для чего же тогда проникали в погребение? Мы выдвигаем довольно смелое, но вероятное предположение, что погребение нарушалось с целью временного изъятия черепа для какихто ритуалов. Культ предков и культ черепа широко известен у многих народов. Возможно, и в данном случае череп был изъят, а после проведения определенных ритуалов возвращен обратно в погребение. По крайней мере, это предположение объясняет имеющуюся совокупность фактов.

В погребении № 4 мы имеем другую картину. Деревянное перекрытие над погребением было частично снято, а потом положено обратно. Под ним находились кости животных в виде типичных «кухонных остатков» (разрозненные и раздробленные). Находились они в слое серой супеси, который покрывал погребенного. Это говорит о том, что кости были помещены в погребение уже после того, как оно было заполнено грунтом. Таким образом, вероятным выглядит предположение, что кости являются результатом поминальных ритуалов. После проведения поминальной трапезы часть перекрытия над погребением № 4 была разобрана, а кости сброшены в погребение. Вероятно, таким образом погребенный стано- вился символическим участником поминальной трапезы.

Отдельно остановимся на методическом аспекте изучения нарушенных захоронений. Как показала практика исследования данного комплекса, если в процессе вскрытия погребения встречаются скопления костей, предметов и т.д. - необходимы промежуточные зачистки и их фиксация. Только в этом случае мы можем получить достоверные данные о способах и процессах нарушения погребения. Единого плана, на котором бы отражались все находки от встречающихся в засыпи до дна, бывает недостаточно, нужны детализированные планы.

\section{Bblводbl}

Таким образом, в погребениях № 3 и 4 выявлены следы постпогребальных ритуалов. В погребении № 3 это манипуляции с останками погребенного, а в погребении № 4 - остатки поминальной трапезы. В обоих случаях ритуалы проводились через значительный промежуток времени (останки прошли стадию скелетирования, a погребения частично заполнились грунтом). Вероятно, общей курганной насыпи в то время еще не существовало, и участники ритуала точно определяли место погребения. При этом они знали расположение погребенных, то есть были и участниками захоронения.

Полученные данные пополняют наши знания о постпогребальных ритуалах населения раннего железного века Западного Казахстана и позволяют уточнить их религиозные практики. 
Бисембаев А.А., Хаванский А.И. Постпогребальные обряды сарматского населения ...

\section{ЛИТЕРАТУРА}

1. Джумабекова Г.С., Базарбаева Г.А. Нарушенные женские погребения сакского времени в Жетысу: по материалам могильника Каспан-6 // Маргулановские чтения - 2019: м-лы Междунар. археол. научн.-практ. конф., посвящ. 95-летию со дня рождения выдающегося казахстанского археолога К.А. Акишева (г. Нур-Султан, 1920 апреля 2019 г.). Нур-Султан: ЕНУ им. Л.Н. Гумилева, 2019. С. 260-270.

2. Очир-Горяева М.А. Следы постпогребальных обрядов в курганах скифской эпохи степей Евразии // Древние некрополи и поселения: постпогребальные ритуалы, символические захоронения и ограбления. Труды ИИМК РАН. СПб.: ИИМК РАН; Невская книжная типография, 2016. Т. 46. С. 113-128.

3. Семёнов Вл.А., Килуновская М.Е. «Разрушение», «разграбление», «ритуал» - погребальный обряд в контексте древних культур (по археологическим памятникам Тувы) // Древние некрополи и поселения: постпогребальные ритуалы, символические захоронения и ограбления. Труды ИИМК РАН. СПб.: ИИМК РАН; Невская книжная типография, 2016. Т. 46. С. 15-36.

4. Яценко С.А., Килуновская М.Е. Нарушенные погребения: проблемы изучения // Древние некрополи и поселения: постпогребальные ритуалы, символические захоронения и ограбления. Труды ИИМК РАН. СПб.: ИИМК РАН; Невская книжная типография, 2016. Т. 46. С. 7-14.

\section{REFERENCES}

1. Jumabekova, G. S., Bazarbayeva, G. A. 2019. In: Margulanovskiye chteniya - 2019 (Margulan readings - 2019). Nur-Sultan: L.N. Gumilyov Eurasian National University, 260-270 (in Russian).

2.Ochir-Goryayeva,M.A.2016.In:Drevniyenekropoli iposeleniya:postpogrebalnyye ritualy, simvolicheskiye zakhoroneniya i ogrableniya (Ancient necropolises and settlements: post-burial rituals, symbolic burials and robberies). Saint Petersburg: Institute for the History of Material Culture of the Russian Academy of Sciences, 113-128 (in Russian).

3. Semonov, Vl. A., Kilunovskaya, M. Ye. 2016. In: Drevniye nekropoli i poseleniya: postpogrebalnyye ritualy, simvolicheskiye zakhoroneniya iogrableniya (Ancient necropolises and settlements: post-burial rituals, symbolic burials and robberies). Saint Petersburg: Institute for the History of Material Culture of the Russian Academy of Sciences, 15-36 (in Russian).

4. Yatsenko, S. A., Kilunovskaya, M. Ye. 2016. In: Drevniye nekropoli i poseleniya: postpogrebalnyye ritualy, simvolicheskiye zakhoroneniya iogrableniya (Ancient necropolises and settlements: post-burial rituals, symbolic burials and robberies). Saint Petersburg: Institute for the History of Material Culture of the Russian Academy of Sciences, 7-14 (in Russian).

Мүдделер қақтығысы туралы ақпаратты ашу. Авторлар мүдделер қақтығысының жоқтығын мәлімдейді. / Раскрытие информации о конфликте интересов. Авторы заявляют об отсутствии конфликта интересов. / Disclosure of conflict of interest information. The authors claims no conflict of interest.

Мақала туралы ақпарат / Информация о статье / Information about the article. Редакцияға түсті / Поступила в редакцию / Entered the editorial office: 24.04.2020. Рецензенттер мақұлдаған / Одобрено рецензентами / Approved by reviewers: 01.06.2020. Жариялауға қабылданды / Принята к публикации / Accepted for publication: 11.06.2020. 